\title{
Celiac Artery Avulsion Secondary to Blunt Trauma: A Case Report and Review of the Literature
}

\author{
Zachary Osborne ${ }^{\mathrm{a}, \mathrm{b}}$, Uretz J Oliphant ${ }^{\mathrm{a}}$, John Aucar ${ }^{\mathrm{a}}$, Michelle M Olson ${ }^{\mathrm{a}}$
}

\begin{abstract}
A 70-year-old male presented with a celiac artery avulsion following a motor vehicle collision. He was hemodynamically stable and complained of severe abdominal pain. A Computed Tomography (CT) scan demonstrated a central supramesocolic retroperitoneal hematoma. There was concern for discontinuity of the celiac artery. At laparotomy, using a left medial visceral rotation, the celiac artery was found completely disrupted and both ends were ligated. He was discharged on post-operative day eleven, without complications. Celiac artery avulsion is reported in $0.01-0.1 \%$ of patients sustaining abdominal vascular injuries. This is only the second reported case of blunt celiac artery avulsion.
\end{abstract}

Keywords: Celiac artery injuries; Blunt trauma; Blunt abdominal trauma

\section{Introduction}

Celiac Artery (CA) injuries are very rare, and often are associated with a high mortality. These injuries are more commonly associated with penetrating trauma. Our case highlights a blunt trauma injury. The majority of the literature on blunt CA injuries is only been published recently, and only 8 articles have published injuries related to blunt CAs.

\section{Case Report}

A 72-year-old male driver, in a head-on motor-vehicle col-

\footnotetext{
Manuscript accepted for publication November 5, 2012

${ }^{\mathrm{a}}$ Carle Foundation Hospital and Illinois College of Medicine, $611 \mathrm{~W}$ Park Urbana, IL 61820, USA

${ }^{\mathrm{b}}$ Corresponding author: Osborne Zachary Jonathan, 611 W Park Urbana, IL 61820, Carle Foundation Hospital and Illinois College of Medicine, USA. Email: Zachary.Osborne@carle.com
}

doi: http://dx.doi.org/10.4021/jmc1009e lision at greater than $60 \mathrm{mph}$, presented to our Level I trauma center. He was restrained, and air bags deployed. The patient's airway, breathing and circulation were intact. His Glasgow Coma Scale (GCS) was 15. The patient was hemodynamically stable, and complained of severe abdominal pain. Secondary survey revealed abdominal tenderness and superficial lacerations. A computer tomography (CT) scan of the patient's head, neck, chest, abdomen and pelvis demonstrated no acute injuries, except for a right hemothorax, and a central supramesocolic retroperitoneal hematoma (Fig. $1,2)$. Sagittal reconstructions showed subtle findings of a hematoma at the origin of the celiac artery interrupted as a disruption of the celiac axis. A chest tube was placed on the right. After consultation with Interventional Radiology and Vascular Surgery, it was determined that exploration was the patient's best option. At laparotomy, using a left medical visceral rotation approach, the celiac artery was found to be completely avulsed. The proximal and distal ends were ligated. The hospitalization was complicated by new onset atrial fibrillation which resolved with medical therapy. The patient was discharged on post-operative day 11. At onemonth follow-up, he had no abdominal complaints.

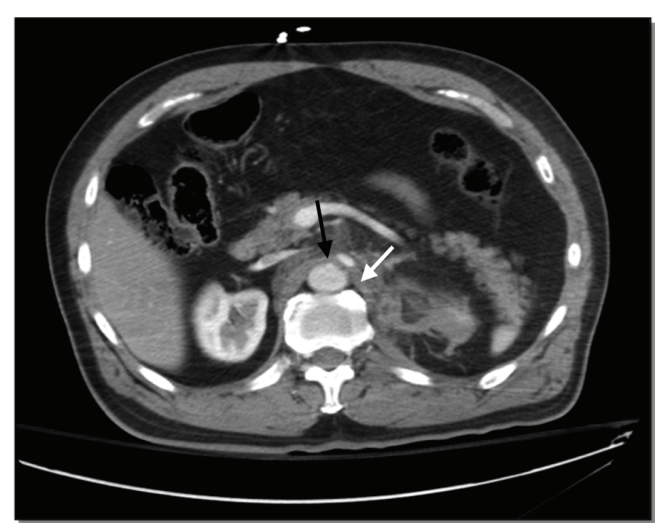

Figure 1. Axial cut CT scan of disruption of celiac artery with associated retroperitoneal hematoma. The white arrow highlights the small retroperitoneal hematoma. The black arrow highlights the disruption of the celiac artery from the aorta. 


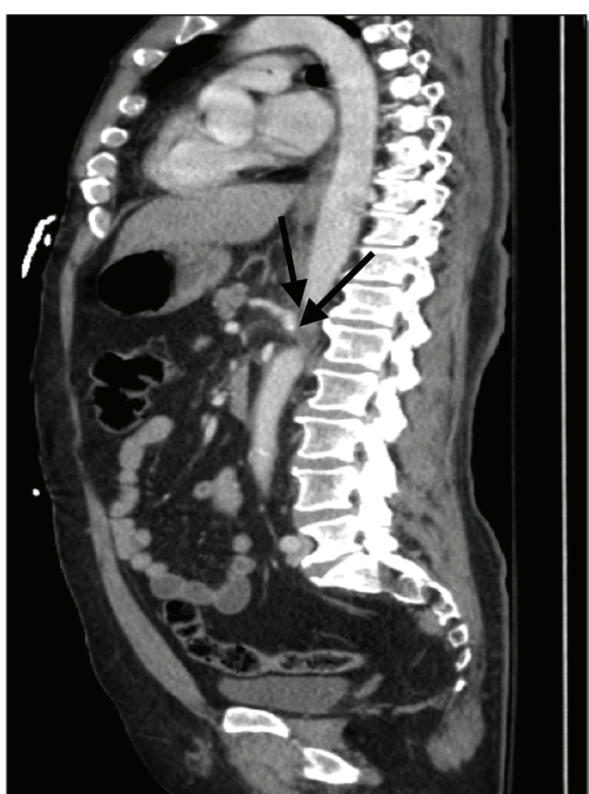

Figure 2. Sagittal reconstruction CT scan demonstrating the disruption of the celiac artery and associated retroperitoneal hematoma. The black arrows demonstrate the discontinuity of the celiac axis origin.

\section{Discussion}

Celiac Artery (CA) injuries are rare, representing 0.01-0.1\% of all visceral vascular injuries $[1,2]$. The overall mortality of abdominal vascular injuries is estimated to be $54 \%$ [3]. This is related to the life-threatening hemorrhage associated with these injuries [4]. With regards to CA injuries specifically, the overall mortality is estimated at $38.5 \%[1,2]$.

A literature search was performed on Medline (1948 2012), using the medical subject headings (MeSH) terms of Celiac Artery, Vascular System Injuries cross-referenced against Wounds and Injuries, Blunt Trauma, Penetrating Trauma, and Abdominal Trauma, as well as, free text search of celiac artery injuries, abdominal vascular injuries. Only articles related to isolated celiac artery injuries were included. This search was supplemented with review of each article's bibliography.

The two largest series of CA injuries report 13 patients each. One reviewed specifically CA injuries [2] and the other described a collection of abdominal vascular injuries including celiac injuries [1]. Four reviews on CA injuries have been published, the latest in 2007; which focused on the hepatic complications following a CA dissection [4-7].

There are 60 documented cases of isolated CA injuries in 17 articles. Of these 60 cases, 8 are related to blunt trauma. These 8 injuries include dissection flaps, occlusions, intimal tears and avulsions (Table 1). To our knowledge, this is the only the second case of a blunt CA avulsion. It is the first case of an isolated blunt CA avulsion in a hemodynamically stable patient. Ten of the 17 articles are either associated with penetrating trauma or the mechanism of injury is unlisted. These are reviewed in prior works $[2,4]$.

A retrospective review, focused on $\mathrm{CA}$ injuries and their management, reported $13 \mathrm{CA}$ injuries. Of the 13 patients one sustained a blunt trauma injury; however, the specific management of each individual's injuries was not stated, only the total management interventions as a whole. The management of these injuries varied, eleven were ligated, one repaired primarily, and one patient expired during the operation [2].

The other 7 reports of CA injuries related to blunt trauma are case reports [6-12]. Multiple different management strategies have been reported in the literature including; observation $[7,8]$, anticoagulation [11], ligation [6, 12] stenting [10], and revascularization [9]. There have reported consequences to occlusion or ligation of the celiac, including hepatic and splenic necrosis [13], hepatic failure [7], and necrosis of the gallbladder [5].

The CA is the first anterior branch of the aorta in the abdomen, giving off the splenic artery, common hepatic, and left gastric. It is just below the diaphragm at the level of the 12th thoracic vertebra. It has been suggested, due to the rich collateral blood flow from the Superior Mesentaric Artery (SMA) through the superior and inferior pancreaticoduodenal arteries as well as the non-named branches from the esophagus, diaphragm, intercostals, and abdominal wall that the CA can be ligated [14]. One must balance the need to control life-threatening hemorrhage versus the risk of hepatic failure or gallbladder necrosis. Nevertheless, ligation of the CA has been documented as a viable option [2, 3, 6, 9]. Our patient tolerated ligation of the $\mathrm{CA}$ well without necrosis of his spleen, liver, or gallbladder.

The suggested pathophysiology of CA injuries includes of the compression of the CA against the median arcuate ligament (MAL) of the diaphragm as the intra-abdominal pressure rapidly increases $[7,15,16]$. This compression could lead to a dissecting intimal flap, or as the fulcrum for a point of tearing in cases of avulsion [4-7].

The establishment proximal and distal control and adequate exposure are the fundamental tenants of vascular surgery. There are four major approaches to establish control of abdominal vessels: left thoracotomy, endovascular balloon occlusion [6], left medial visceral rotation [17], and direct midline compression at the aortic hiatus, or through the mesentery [18].

Hematomas of the central abdomen upper abdomen can mean injury to the suprarenal aorta, CA, proximal SMA, proximal renal arteries, or the inferior vena cava. It is generally recommended to explore these due to the risk of exsanguination. Angiography can be helpful in planning an approach; however, distal control is very difficult if not impossible in cases of avulsion.

There are four techniques for management of a CA injury. These include: primary repair, surgical bypass, endo- 


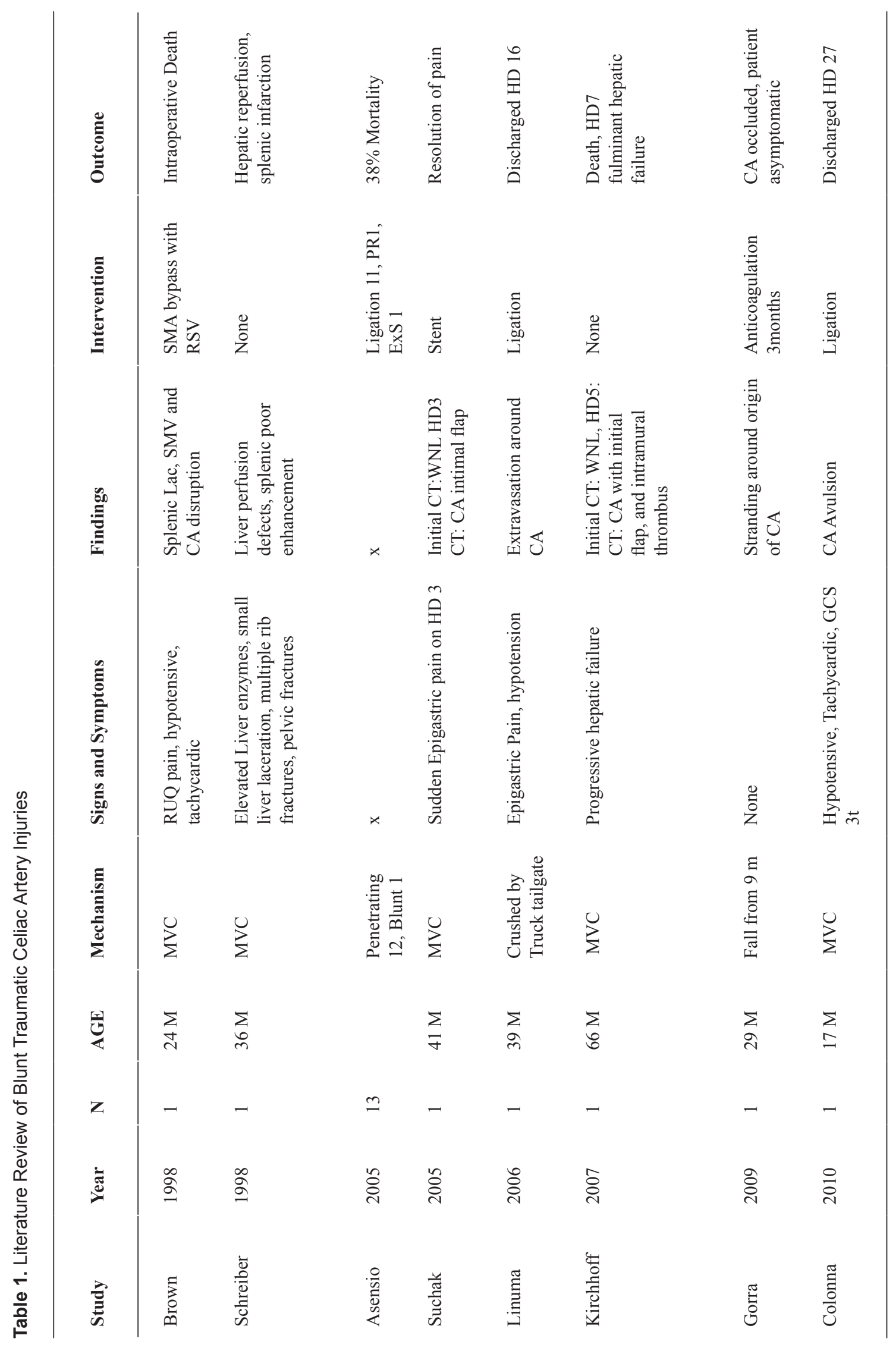


vascular stenting or embolization, or ligation. Primary repair has been advocated in the literature as the preferred approach; however ligation is an acceptable $[1,2,14]$. Surgical bypass with an interposition graft of vein or prosthetic material is undertaken if the other major vessels of the abdomen have been injured $[3,9]$.

\section{Conclusion}

The current case represents the second reported CA avulsion related to blunt trauma. It is the first case in the literature of an isolated blunt CA avulsion in a hemodynamically stable patient. The decision to operatively explore this patient was based on the fact that this was central supramesocolic hematoma and there was some question if the proximal left renal artery was involved. Consultation with vascular surgery and interventional radiology was obtained. We performed a left medial rotation of the viscera. Ligation was the selected treatment on the basis of adequate collateral circulation. The patient had no complications related to ligation of the CA including liver injury or necrosis of his gallbladder.

\section{Disclaimer}

All authors have no conflict of interest in this report.

\section{References}

1. Graham JM, Mattox KL, Beall AC, Jr., DeBakey ME. Injuries to the visceral arteries. Surgery. 1978;84(6):835839.

2. Asensio JA, Petrone P, Kimbrell B, Kuncir E. Lessons learned in the management of thirteen celiac axis injuries. South Med J. 2005;98(4):462-466.

3. Asensio JA, Chahwan S, Hanpeter D, Demetriades D, Forno W, Gambaro E, Murray J, et al. Operative management and outcome of 302 abdominal vascular injuries. Am J Surg. 2000;180(6):528-533; discussion 533-524.

4. Asensio JA, Forno W, Roldan G, Petrone P, Rojo E, Ceballos J, Wang C, et al. Visceral vascular injuries. Surg Clin North Am. 2002;82(1):1-20, xix.

5. Kavic SM, Atweh N, Ivy ME, Possenti PP, Dudrick SJ. Celiac axis ligation after gunshot wound to the abdomen: case report and literature review. J Trauma. 2001;50(4):738-739.
6. Linuma Y, Yamazaki Y, Hirose Y, Kinoshita H, Kumagai K, Tanaka T, Miyajima M, et al. A case of isolated celiac axis injury by blunt abdominal trauma. J Trauma. 2006;61(2):451-453.

7. Kirchhoff C, Stegmaier J, Krotz M, Muetzel Rauch E, Mutschler W, Kanz KG, Heindl B. Celiac dissection after blunt abdominal trauma complicated by acute hepatic failure: case report and review of literature. J Vasc Surg. 2007;46(3):576-580.

8. Schreiber JP, Angle JF, Matsumoto AH, Young JS, Hagspiel KD, Spinosa DJ. Acute visceral ischemia occurring subsequent to blunt abdominal trauma: potential culpability of median arcuate ligament compression. J Trauma. 1998;45(2):404-406.

9. Brown DB, Singh H, Atnip RG, Cardella JF, Waybill PN. Blunt traumatic injury to the superior mesenteric artery and celiac axis. J Vasc Interv Radiol. 1998;9(5):783785 .

10. Suchak AA, Reich D, Ritchie W. Traumatic isolated dissection of the celiac artery. AJR Am J Roentgenol. 2007;189(6):W373-374.

11. Gorra AS, Mittleider D, Clark DE, Gibbs M. Asymptomatic isolated celiac artery dissection after a fall. Arch Surg. 2009;144(3):279-281.

12. Colonna AL, Enniss TM, Meredith JW, Hildreth AN. Celiac artery avulsion and right atrial rupture after blunt multisystem trauma. Am Surg. 2010;76(7):E83-85.

13. Francque S, Condat B, Asselah T, Vilgrain V, Durand F, Moreau R, Valla D. Multifactorial aetiology of hepatic infarction: a case report with literature review. Eur J Gastroenterol Hepatol. 2004;16(4):411-415.

14. Goaley TJ, and Feliciano DV, Abdominal Vascular Injuries, 410-415: In Asensio JA, Trunkey DD. Current Therapy of Trauma and Surgical Critical Care. Portland, Mosby Inc. 2008.

15. Lindner $\mathrm{HH}$, Kemprud E. A clinicoanatomical study of the arcuate ligament of the diaphragm. Arch Surg. 1971;103(5):600-605.

16. Stoney RJ, Wylie EJ. Recognition and surgical management of visceral ischemic syndromes. Ann Surg. 1966;164(4):714-722.

17. Mattox KL, McCollum WB, Beall AC, Jr., Jordan GL, Jr., Debakey ME. Management of penetrating injuries of the suprarenal aorta. J Trauma. 1975;15(9):808-815.

18. Feliciano DV: Abdominal vascular injury. Trauma, 5th ed. Moore EE, Feliciano DV, Mattox KL, Eds. McGrawHill, New York, 2004. 